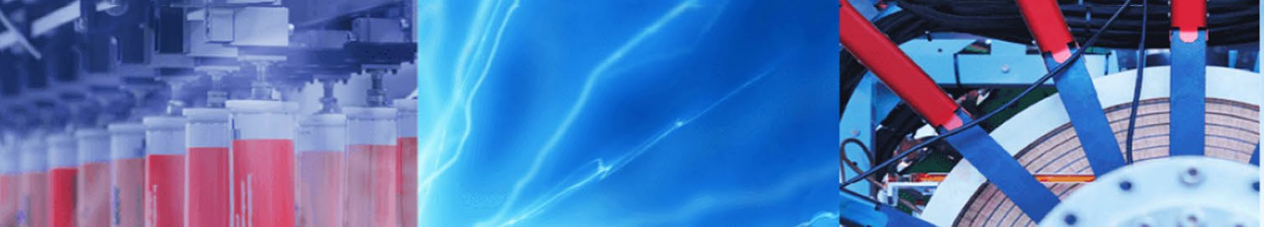

Research Article

\title{
Designing a new method to remove carbon dioxide as an environmental pollutant and produce methanol
}

\author{
Mahdi Sagharizade $^{1} \cdot$ Tahereh Asadi $^{1} \cdot$ Bahador Abolpour $^{1}$ (I)
}

(c) Springer Nature Switzerland AG 2019

\begin{abstract}
Carbon dioxide is one of the flue gases emitted from fossil fuels that are harmful to the environment and humans. Producing valuable methanol from syngas is a proper method to recover $\mathrm{CO}_{2}$ without requiring pretreatment. In this study, a new method is developed to produce methanol from flue gases emitted from fossil fuels. This process is simulated using Aspen Plus 8.0 software, and the results are compared with the data obtained by previous researches. Results confirmed the accuracy of the calculations and efficiency of the newly designed process. The purity of the produced methanol and the operational conditions are improved in this simulation.
\end{abstract}

Keywords Methanol · Carbon dioxide · Flue gas

\section{Introduction}

Nowadays, $\mathrm{CO}_{2}$ removing and converting it into valuable products have become very important throughout the world. Removing it due to environmental requirements is not only for its hazardous impacts on global weather, but also for its unknown potential to produce some worthy materials $[1,2]$. Separation of $\mathrm{CO}_{2}$ from other waste products is a cost-benefit process and is not complicated [3-7]. The produce of methanol from syngas is a proper method to recover $\mathrm{CO}_{2}$ without requiring pretreatment $[8,9]$. In this process, methane gas is also injected as a hydrogen supplier. The $\mathrm{CO}_{2}$ dry reforming and methane oxidation have been proposed by researchers for utilizing $\mathrm{CO}_{2}$ with no pre-purification [3]. Attending the production of carbon (soot) in this method and deactivation of catalysts in reactor, subsequently, the carbon formation in the syngas production reactor should reduce to its minimum [10-12].

Injecting $\mathrm{H}_{2} \mathrm{O}$ and $\mathrm{O}_{2}$ into the process reduces the carbon formation on catalysts. In addition, the ratio of produced $\mathrm{H}_{2}$ to $\mathrm{CO}$ in this reactor, which are the basic materials for producing methanol, should be designed in a desirable range [13-15]. There are several studies that investigated the $\mathrm{CO}_{2}$ removing using the described method [16, 17], but few studies focused on the methanol production potential of this method [8].

In this study, a novel process for producing methanol from the flue gas has been presented using the Aspen Plus 8.0 software. The purity percentage of the produced methanol and working conditions have been improved in this simulation. The results of simulation have been validated using data obtained in the earlier similar researches. The aim of this study is designing an economical process for industries producing high-purity methanol from the flue gas. For this purpose, industrial data of flue gas have been used.

\section{Simulation of process}

Simulation of methanol production from flue gasses has been performed using the Aspen Plus 8.0 software. The new design has been based on high purity, low capital and operational costs, and also reducing the cost of

Bahador Abolpour, bahadorabolpor1364@sirjantech.ac.ir| 'Department of Chemical Engineering, Sirjan University of Technology, Sirjan 7813733385, Iran.

SN Applied Sciences (2019) 1:994 | https://doi.org/10.1007/s42452-019-0964-8 


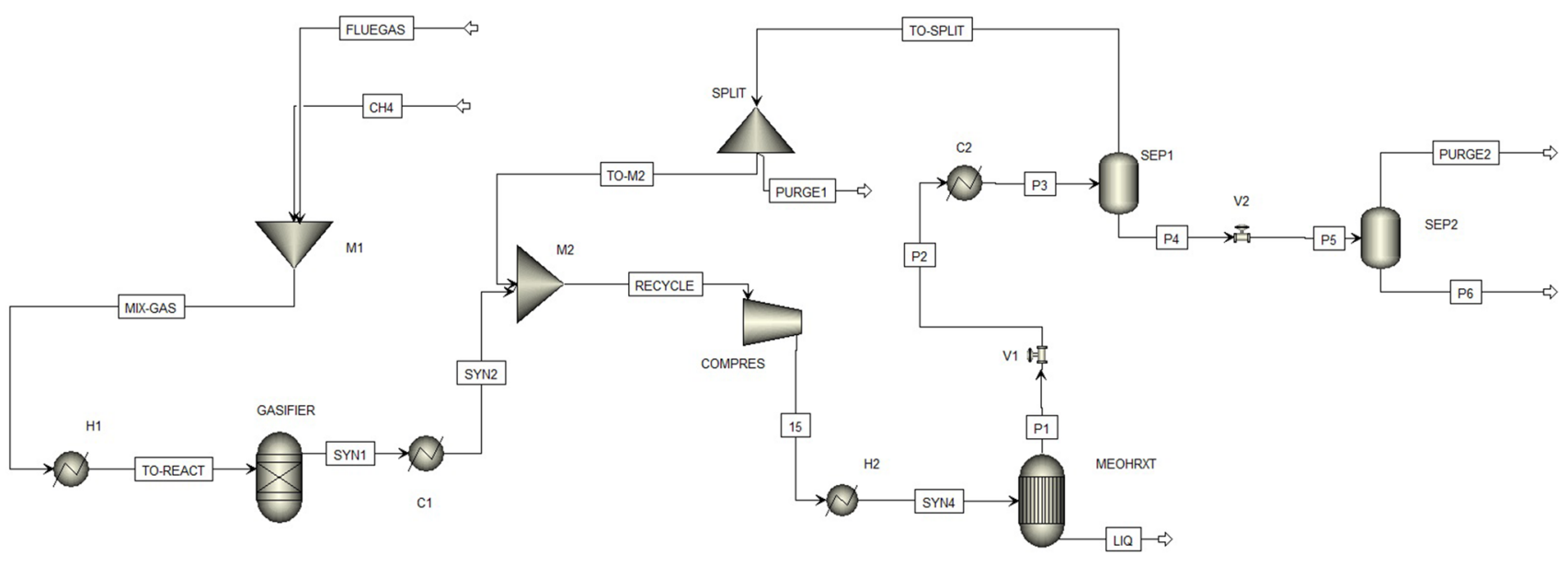

Fig. 1 Process flow sheet of methanol production from flue gas and methane as reactants

Table 1 The composition of flue gas stream (mol\%)

conservation/storage of methanol at high temperatures and pressures.

Figure 1 shows the process flow diagram of high-quality methanol production from the flue gasses and natural gas. $\mathrm{M} 1$ is a mixer to mix flue and $\mathrm{CH}_{4}$ gases that pass the heater $\mathrm{h} 1$, for increasing its temperature, and that enter a gasifier reactor to produce the syngas. The syngas temperature is decreased in $C 1$, and this gas is mixed with a recycled and purged gas in $\mathrm{M} 2$, is compressed and also heated up in compressor-heater $(\mathrm{H} 2)$, and finally is injected into the MEOHRTX to produce methanol. The produced methanol should be separated and purified in a suitable separator.

In this study, the defined flue gas properties have been extracted from the published data from an industrial unit [8]. Composition of the used stream is shown in Table 1. This table shows that the input stream consists of both $\mathrm{CO}_{2}$ and $\mathrm{H}_{2} \mathrm{O}$, which reacted together and produced methanol. The molar flow rate and temperature of the stream are $1000 \mathrm{kmol} / \mathrm{h}$ and $150{ }^{\circ} \mathrm{C}$, respectively. Moreover, a methane stream (natural gas at STP conditions) is fed into the system, as another feed.

In the newly designed process, two reactors have been applied. The first reactor is of RGIBBS type (based on minimization the Gibbs energy of system) and is used to
Table 2 The set of reactions

\begin{tabular}{llc}
\hline Reactor & Reaction & Number \\
\hline RGIBBS & $\mathrm{CO}_{2}+\mathrm{CH}_{4} \rightarrow 2 \mathrm{CO}+2 \mathrm{H}_{2}$ & 1 \\
& $\mathrm{H}_{2} \mathrm{O}+\mathrm{CH}_{4} \rightarrow \mathrm{CO}+3 \mathrm{H}_{2}$ & 2 \\
& $1 / 2 \mathrm{O}_{2}+\mathrm{CH}_{4} \rightarrow \mathrm{CO}+2 \mathrm{H}_{2}$ & 3 \\
& $2 \mathrm{O}_{2}+\mathrm{CH}_{4} \rightarrow \mathrm{CO}_{2}+2 \mathrm{H}_{2} \mathrm{O}$ & 4 \\
& $\mathrm{CH}_{4} \rightarrow \mathrm{C}+2 \mathrm{H}_{2}$ & 5 \\
& $2 \mathrm{CO} \rightarrow \mathrm{C}+\mathrm{CO}_{2}$ & 6 \\
& $\mathrm{C}+\mathrm{CO}_{2} \rightarrow 2 \mathrm{CO}$ & 7 \\
& $\mathrm{C}+\mathrm{H}_{2} \mathrm{O} \rightarrow \mathrm{CO}+\mathrm{H}_{2}$ & 8 \\
& $\mathrm{C}+\mathrm{O}_{2} \rightarrow \mathrm{CO}_{2}$ & 9 \\
REQUIL & $2 \mathrm{H}_{2}+\mathrm{CO} \rightarrow \mathrm{CH}_{3} \mathrm{OH}$ & 10 \\
& $\mathrm{CO}+3 \mathrm{H}_{4} \rightarrow \mathrm{CH}_{3} \mathrm{OH}+\mathrm{H}_{2} \mathrm{O}$ & 11 \\
& $\mathrm{CO}+\mathrm{H}_{2} \mathrm{O} \rightarrow \mathrm{CO}_{2}+\mathrm{H}_{2}$ & 12 \\
\hline
\end{tabular}

generate syngas (1-9). The second one is of REQUIL type (based on thermodynamic calculations) and is used to generate methanol (10-12). Table 2 presents the set of the relevant reactions to these reactors. The presented reactions in the RGIBBS reactor produce the $\mathrm{CO}$ and $\mathrm{H}_{2}$ gases, which are required to produce methanol. These components react together in the REQUIL reactor and produce methanol. The mixture gas produced in the first reactor is cooled down to $220^{\circ} \mathrm{C}$ and is pressurized up to 50 bar, which are required at the methanol synthesis reactor. $A$ three-stage compressor is used to create such pressure. Reactions (10 and 11) are the main reactions for methanol production that occurs inside this reactor, while the reaction (12) is a side reaction. $\mathrm{N}_{2}$, as a flue stack part from 
Table 3 Operating conditions for methanol production

\begin{tabular}{lcc}
\hline Flow sheet element & Temperature $\left({ }^{\circ} \mathrm{C}\right)$ & Pressure (bar) \\
\hline Methanol reactor & 220 & 50 \\
Sep1 (adiabatic) & 25 & 24 \\
Sep2 (adiabatic) & 25 & 1 \\
\hline
\end{tabular}

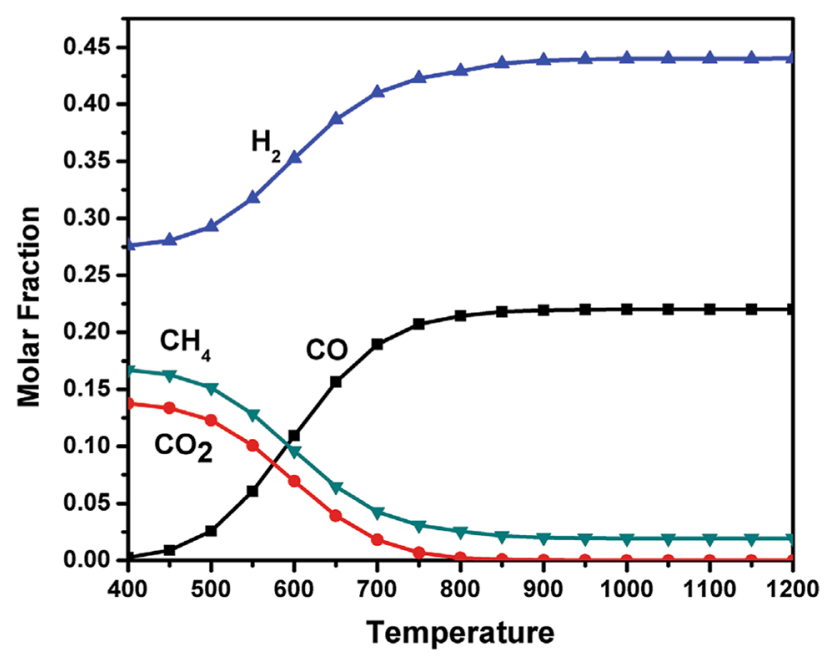

Fig. 2 Effect of temperature on equilibrium product composition at $\mathrm{CH}_{4} /$ flue gas $=0.4$ and pressure $=1 \mathrm{~atm}$ in GASIFIER [8]

the combustion of furnaces in power plants, inputs the designed system and reduces methanol production rate. Therefore, a gas cycle has been formed to make a higher percentage of methanol production and recover the reaction. In the recycle stream, the produced gas returned to the reactor. A separator has been placed here (Sep1) for the partial separation of impurities, which helps to remove waste gases. In the last step, another separator (Sep2) has been embedded that separates almost all $\mathrm{N}_{2}$ from methanol. Operating conditions for the methanol production are listed in Table 3.

Based on the previous study [8], the temperature of the gas synthesis reactor, its pressure and the ratio of inlet molar flows were ranged from 400 to $1200^{\circ} \mathrm{C}$ (Fig. 2), 1 to $5 \mathrm{~atm}$ (Fig. 3), and 0.4 to 1 (Fig. 4), respectively, and the most appropriate values for these variables were obtained. The mole fraction of carbon monoxide has been increased by increasing the temperature to its maximum value at $850^{\circ} \mathrm{C}$, but the fraction of $\mathrm{CO}_{2}$ has been decreased to zero at this temperature. Therefore, $\mathrm{CO}_{2}$ is the limiting reactant for the reaction.
Increasing the temperature increases the mole fraction of $\mathrm{H}_{2}$ and decreases the mole fraction of $\mathrm{CH}_{4}$. It shows a significant relationship between $\mathrm{CH}_{4}$ consumption and $\mathrm{H}_{2}$ production. Increasing $\mathrm{CH}_{4}$ /flue gas ratio increases the $\mathrm{H}_{2}$ molar flow, but at the temperatures up to $850^{\circ} \mathrm{C}$, this relationship has been broken down. The $\mathrm{CH}_{4}$ /flue gas ratio also affects $\mathrm{CO}$ production, and $\mathrm{CO}$ flow rate starts to increase from zero at $400^{\circ} \mathrm{C}$. Increasing this ratio also increases the $\mathrm{CO}_{2}$ production. Increasing the pressure from 1 to $5 \mathrm{~atm}$ decreases the hydrogen fraction and increases the methane fraction. At temperatures up to $100^{\circ} \mathrm{C}$, the pressure effect is negligible. According to these data, the best temperature and pressure for gasifier reactors are $850{ }^{\circ} \mathrm{C}$ and $1 \mathrm{~atm}$, respectively. In addition, the best ratio of methane to flue gas is $0.4 \%$.

\section{Results and discussion}

The properties of inlet and middle streams of this simulation are presented in Table 4. The archived data show the suitable separation of nitrogen in SEP2. It is also clear that the carbon dioxide is produced in the equilibrium reactor, which shows that the reaction 12 is more favored than the reaction 11 in this setup. The temperature and pressure of the gas synthesis reactor were set at $400{ }^{\circ} \mathrm{C}$ and $1 \mathrm{~atm}$, respectively. In addition, the input streams (flow rate of methane and flue gas) were set at 400 and $1000 \mathrm{kmol} / \mathrm{hr}$, respectively.

In the similar study [8], an equilibrium distillation tower was used to increase the percentage of methanol purity. Manufacturing and maintenance of this tower have many expenses, as well as the supply of heat energy for re-boiling and condensing. One of the advantages of this study is the production of a high-purity methanol by optimizing the control parameters and without using a distillation tower.

Table 5 lists the characteristics of the main streams of the proposed process. Figure 5 shows a comparison between the molar stream flows in the new proposed process (1) and in the pervious similar one (2), which used a distillation tower instead of optimizing the parameters. The results show that the methanol purity for process (1) is $99.69 \%$ and greater than 99.57 in process (2). In addition, in Fig. 6, a similar comparison between the energy consumption of these two 

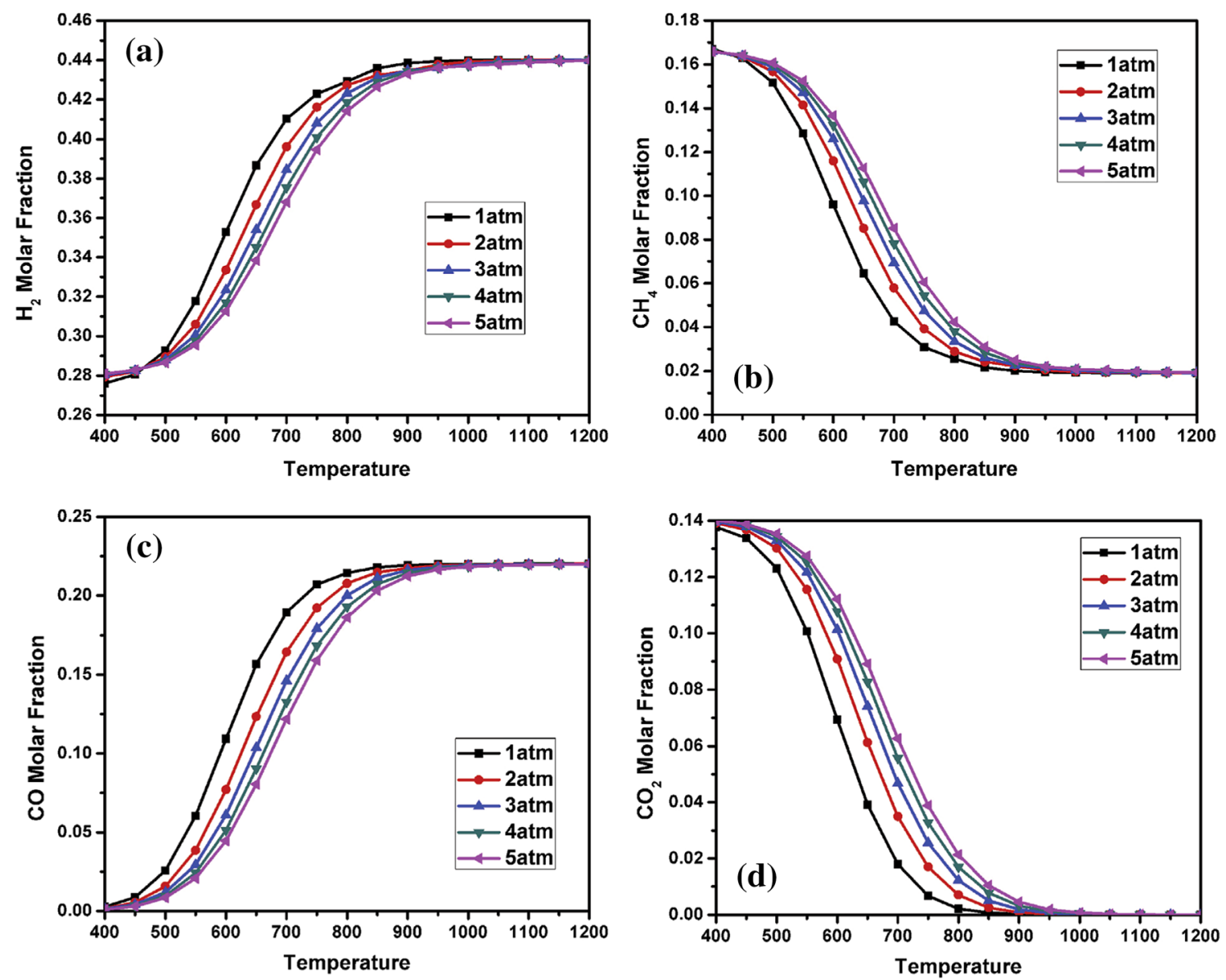

Fig. 3 Effect of reaction pressure on equilibrium a hydrogen, $\mathbf{b}$ methane, $\mathbf{c}$ carbon monoxide, $\mathbf{d}$ carbon dioxide in GASIFIER [8]

processes has been shown. It is clear that a significant decrement (about 19\%) in energy consumption has happened in this newly proposed process.

In this study, by making pressure changes in the pressure reducer valve and last separator, the pressure has been decreased to a standard value. These changes reduce the cost, by eliminating the distillation tower. Furthermore, conditions that are more comfortable have been determined for saving methanol in the reservoirs. Figure 7 shows a comparison between temperature and pressure of these systems, with distillation column and without it. It is clear that the newly designed process has a lower temperature and pressure than the designed process in the previous study [8].

\section{Conclusion}

In the presented study, the production of methanol from flue gasses was simulated using the Aspen Plus 8.0 software. The temperature and pressure of the gas production reactor and the molar ratio of $\mathrm{CH}_{4} /$ flue gas were optimized, 

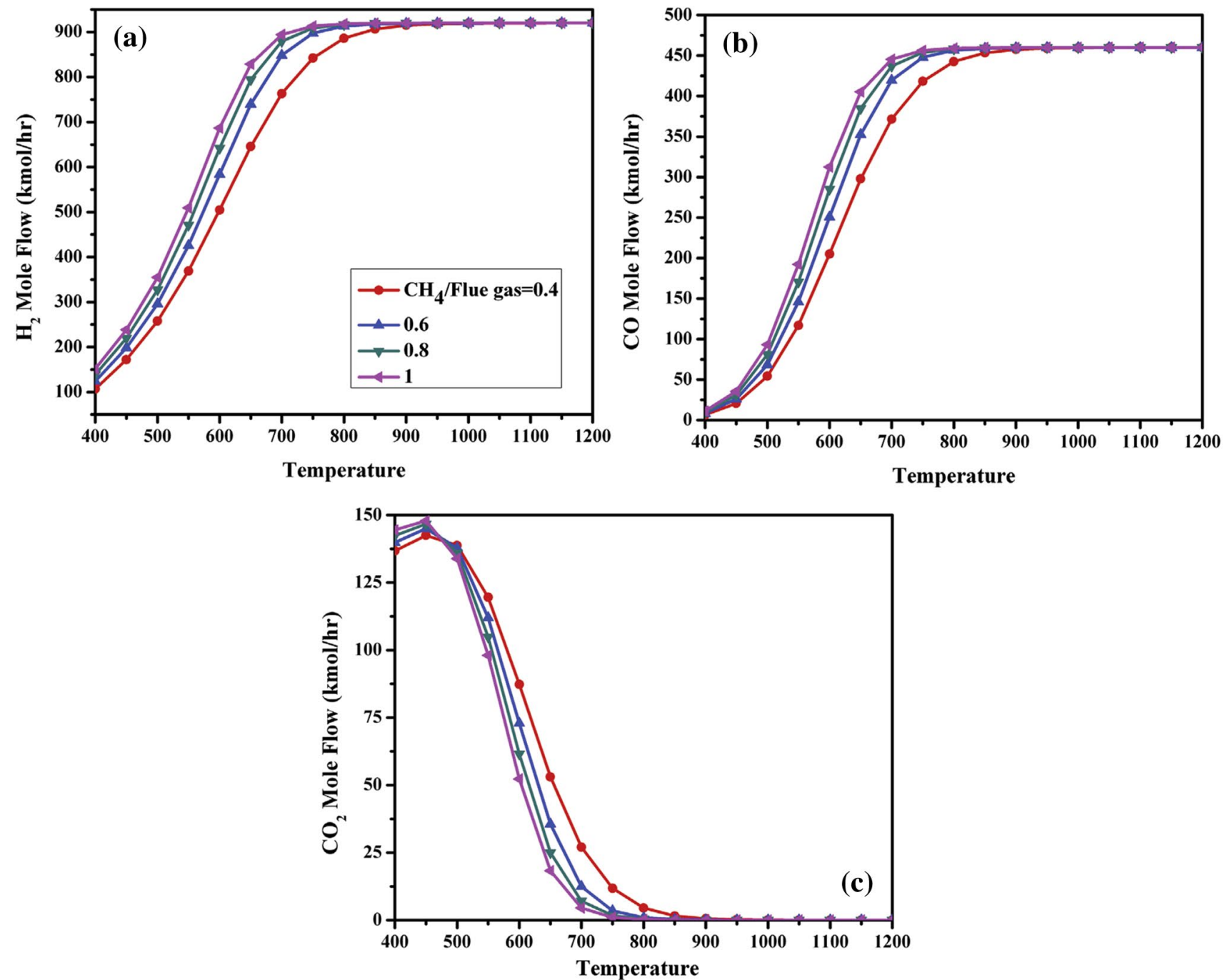

Fig. 4 Effect of $\mathrm{CH}_{4}$ /flue gas ratio on equilibrium a hydrogen, $\mathbf{b}$ carbon monoxide, $\mathbf{c}$ carbon dioxide in GASIFIER [8] 
Table 4 Inlet and middle streams specifications

\begin{tabular}{|c|c|c|c|c|c|c|}
\hline & $\mathrm{CH}_{4}$ & FLUEGAS & MIX-GAS & MIX-GAS & TO-REACT & SYN1 \\
\hline $\mathrm{CH}_{4}$ & 400 & 0 & 400 & 400 & 400 & 44.9918 \\
\hline $\mathrm{CO}_{2}$ & 0 & 100 & 100 & 100 & 100 & 1.5704 \\
\hline $\mathrm{CO}$ & 0 & 0 & 0 & 0 & 0 & 453.438 \\
\hline $\mathrm{H}_{2}$ & 0 & 0 & 0 & 0 & 0 & 906.595 \\
\hline $\mathrm{O}_{2}$ & 0 & 30 & 30 & 30 & 30 & $1.5451 \times 10^{-19}$ \\
\hline $\mathrm{H}_{2} \mathrm{O}$ & 0 & 200 & 200 & 200 & 200 & 3.42141 \\
\hline C & 0 & 0 & 0 & 0 & 0 & $5.4209 \times 10^{-22}$ \\
\hline $\mathrm{N}_{2}$ & 0 & 670 & 670 & 670 & 670 & 670 \\
\hline METHANOL & 0 & 0 & 0 & 0 & 0 & $6.58933 \times 10^{-7}$ \\
\hline Total flow, kmol/h & 400 & 1000 & 1400 & 1400 & 1400 & 2080.02 \\
\hline Total flow, kg/h & 6417.1 & 27,733 & $34,150.1$ & $34,150.1$ & $34,150.1$ & $34,150.1$ \\
\hline Total flow, l/min & 162,734 & 578,312 & 732,225 & 732,225 & $2.1794 \times 10^{6}$ & $3.19563 \times 10^{6}$ \\
\hline Temperature, ${ }^{\circ} \mathrm{C}$ & 25 & 150 & 109.664 & 109.664 & 850 & 850 \\
\hline Pressure, bar & 1.01325 & 1.01325 & 1.01325 & 1.01325 & 1 & 1.01325 \\
\hline Vapor frac & 1 & 1 & 1 & 1 & 1 & 1 \\
\hline Liquid frac & 0 & 0 & 0 & 0 & 0 & 0 \\
\hline Solid frac & 0 & 0 & 0 & 0 & 0 & 0 \\
\hline Enthalpy, cal/mol & $-17,803.2$ & $-20,019.8$ & $-19,386.5$ & $-19,386.5$ & $-11,987.5$ & -188.705 \\
\hline Enthalpy, cal/gml & -1109.73 & -721.877 & -794.758 & -794.758 & -491.434 & -11.4937 \\
\hline Enthalpy, cal/s & $-1.9781 \times 10^{6}$ & $-5.5611 \times 10^{6}$ & $-7.5392 \times 10^{6}$ & $-7.5392 \times 10^{6}$ & $-4.6618 \times 10^{6}$ & $-109,030$ \\
\hline Entropy, cal/mol K & -19.2605 & 2.39455 & -2.50402 & -2.50402 & 7.92369 & 16.2063 \\
\hline Entropy, cal/gm K & -1.20057 & 0.086343 & -0.102654 & -0.102654 & 0.324835 & 0.987094 \\
\hline Density, $\mathrm{mol} / \mathrm{cc}$ & $4.09666 \times 10^{-5}$ & $2.88195 \times 10^{-5}$ & $3.18663 \times 10^{-5}$ & $3.18663 \times 10^{-5}$ & $1.07063 \times 10^{-5}$ & $1.08482 \times 10^{-5}$ \\
\hline Density, gm/cc & 0.000657218 & 0.000799252 & 0.000777314 & 0.000777314 & 0.000261158 & 0.000178108 \\
\hline Average, MW & 16.0428 & 27.733 & 24.393 & 24.393 & 24.393 & 16.4182 \\
\hline Liq Vol 60F, I/min & 357.052 & 774.271 & 1131.32 & 1131.32 & 1131.32 & 1856.66 \\
\hline
\end{tabular}

as well. The main advantage of the newly designed process was its ability to produce high-purity methanol with low costs, which is derived from conservation and storage of methanol at standard temperature and pressure. In order to facilitate the industrial use of this newly designed process, real data of a flue gas of an industrial unit were used as input stream for simulation. The newly designed method leads to significant reduction in costs and energy consumption (19\% reduction) by eliminating the distillation tower, high-purity methanol (99.69\%) and simpler storage conditions, by applying pressure corrections in various parts of the process. The simulated data showed the profitability of the newly designed process and the introduced reactors and separators to produce methanol from the inlet gases. It was shown that the newly designed process works at lower temperature and pressure than the other designed processes in the similar previous studies. Finally, the results confirmed that the proposed process has the ability to produce this valuable material (methanol) from carbon dioxide, as an environmental pollutant, with low capital and operating costs. 
Table 5 Stream results from methanol production via removing the distillation tower and pressure corrections

\begin{tabular}{|c|c|c|c|c|c|}
\hline & SYN1 & P4 & PURGE1 & PURGE2 & P6 \\
\hline $\mathrm{CH}_{4}$ & 44.9918 & 0.333417 & 44.6554 & 0.305948 & 0.0274691 \\
\hline $\mathrm{CO}_{2}$ & 1.5704 & 0.292196 & 3.78457 & 0.148134 & 0.144062 \\
\hline $\mathrm{CO}$ & 453.438 & 0.0845544 & 61.5636 & 0.0832253 & 0.00132917 \\
\hline $\mathrm{H}_{2}$ & 906.595 & 0.0626598 & 130.305 & 0.062326 & 0.000333837 \\
\hline $\mathrm{O}_{2}$ & $1.5451 \times 10^{-19}$ & 0 & 0 & 0 & 0 \\
\hline $\mathrm{H}_{2} \mathrm{O}$ & 3.42141 & 0.910275 & 0.00513507 & 0.000369681 & 0.909905 \\
\hline C & $5.4209 \times 10^{-22}$ & 0 & 0 & 0 & 0 \\
\hline $\mathrm{N}_{2}$ & 670 & 2.31504 & 667.64 & 2.22489 & 0.0901467 \\
\hline METHANOL & $6.58933 \times 10^{-7}$ & 381.158 & 8.13839 & 0.539519 & 380.618 \\
\hline Total flow, kmol/h & 2080.02 & 385.156 & 916.092 & 3.36441 & 381.792 \\
\hline Total flow, kg/h & $34,150.1$ & $12,315.1$ & $21,833.9$ & 93.5054 & $12,221.6$ \\
\hline Total flow, l/min & $3.19563 \times 10^{6}$ & 259.74 & $15,667.1$ & 1367.81 & 256.852 \\
\hline Temperature, ${ }^{\circ} \mathrm{C}$ & 850 & 25 & 25 & 25 & 25 \\
\hline Pressure, bar & 1.01325 & 24 & 24 & 1.01325 & 1.01325 \\
\hline Vapor frac & 1 & 0 & 1 & 1 & 0 \\
\hline Liquid frac & 0 & 1 & 0 & 0 & 1 \\
\hline Solid frac & 0 & 0 & 0 & 0 & 0 \\
\hline Enthalpy, cal/mol & -188.705 & $-57,266.2$ & -3494.64 & $-14,118.5$ & $-57,655.7$ \\
\hline Enthalpy, cal/gm & -11.4937 & -1791.01 & -146.626 & -507.997 & -1801.12 \\
\hline Enthalpy, cal/s & $-109,030$ & $-6.1268 \times 10^{6}$ & $-889,280$ & $-13,194.6$ & $-6.1146 \times 10^{6}$ \\
\hline Entropy, cal/mol K & 16.2063 & -59.088 & -4.38478 & -4.00693 & -59.4834 \\
\hline Entropy, cal/gm K & 0.987094 & -1.84799 & -0.183974 & -0.144173 & -1.85821 \\
\hline Density, $\mathrm{mol} / \mathrm{cc}$ & $1.0848 \times 10^{-5}$ & 0.0247141 & 0.000974541 & $4.09951 \times 10^{-5}$ & 0.0247738 \\
\hline Density, gm/cc & 0.000178108 & 0.790217 & 0.0232268 & 0.00113935 & 0.793037 \\
\hline Average, MW & 16.4182 & 31.9743 & 23.8337 & 27.7925 & 32.0111 \\
\hline Liq Vol 60F, I/min & 1854.66 & 259.261 & 815.935 & 2.88406 & 256.377 \\
\hline
\end{tabular}

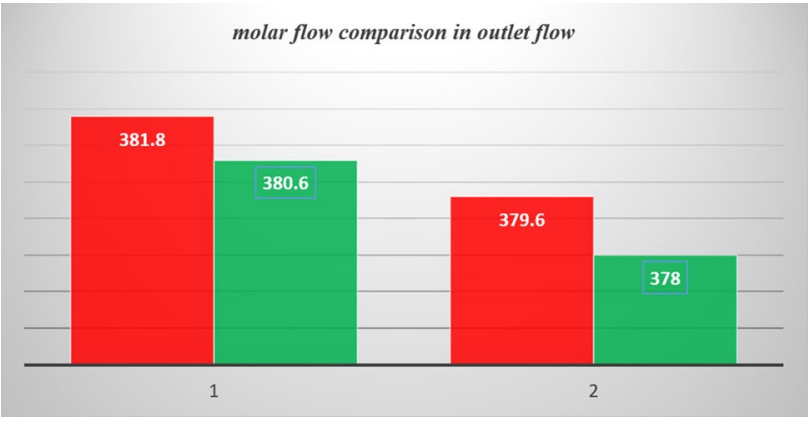

Fig. 5 Comparison between molar flow $(\mathrm{kmol} / \mathrm{h})$ of methanol (green color), output streams (red color) and the (1) suggested method, (2) with a similar process without pressure corrections and by using a distillation tower

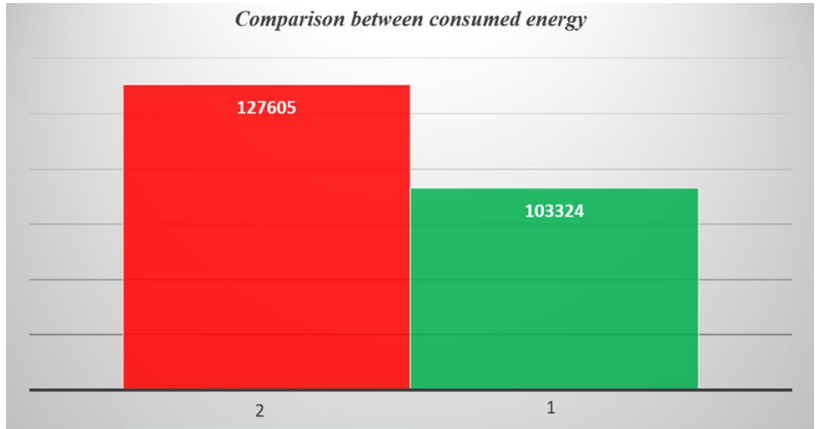

Fig. 6 Comparison between consumed energy (kw) in two systems: without tower (green color) and with tower (red color) 
Comparison between output pressure and temperature

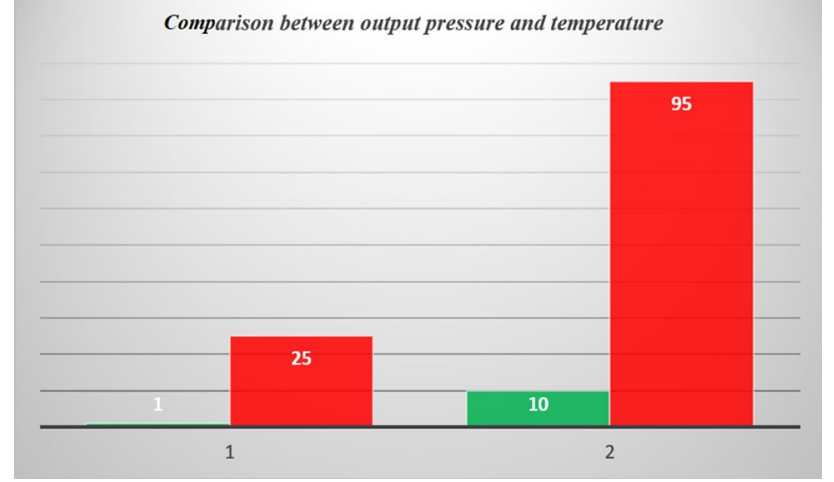

Fig. 7 Comparison between outlet pressure (bar) (green color) and temperature $\left({ }^{\circ} \mathrm{C}\right)$ (red color) in two systems: (1) without tower; (2) with tower

\section{Compliance with ethical standards}

Conflict of interest The authors declare that they have no conflict of interest.

Informed consent The research involved no human participants.

\section{References}

1. Minutillo M, Perna A (2009) A novel approach for treatment of $\mathrm{CO}_{2}$ from fossil fired power plants, part $\mathrm{A}$ : the integrated systems ITRPP. Int J Hydrogen Energy 34:4014-4020

2. Song C (2006) Global challenges and strategies for control, conversion and utilization of $\mathrm{CO}_{2}$ for sustainable development involving energy, catalysis, adsorption and chemical processing. Catal Today 115:2-32

3. Song C, Pan W (2004) Tri-reforming of methane: a novel concept for catalytic production of industrially useful synthesis gas with desired $\mathrm{H}_{2} / \mathrm{CO}$ ratios. Catal Today 98:463-484

4. Sadeghi M, Jafari M, Yari M, Mahmoudi SMS (2018) Exergoeconomic assessment and optimization of a syngas production system with a desired $\mathrm{H}_{2} / \mathrm{CO}$ ratio based on methane trireforming process. J CO2 Util 25:283-301

5. Aboosadi ZA, Jahanmiri AH, Rahimpour MR (2011) Optimization of tri-reformer reactor to produce synthesis gas for methanol production using differential evolution (DE) method. Appl Energy 88:2691-2701

6. Gangadharan P, Zanwar A, Zheng K, Gossage J, Lou HH (2012) Sustainability assessment of polygeneration processes based on syngas derived from coal and natural gas. Comput Chem Eng 39:105-117

7. Sunny A, Solomon PA, Aparna K (2016) Syngas production from regasified liquefied natural gas and its simulation using Aspen HYSYS. J Natl Gas Sci Eng 13:176-181

8. Zhang Y, Cruz J, Zhang S, Lou HH, Benson TJ (2013) Process simulation and optimization of methanol production coupled to trireforming process. Int J Hydrogen Energy 38:13617-13630

9. Zhang Y, Xiao J, Shen L (2009) Simulation of methanol production from biomass gasification in interconnected fluidized beds. Ind Eng Chem Res 48:5351-5359

10. Rostrup-Nielsen J, Trimm DL (1977) Mechanisms of carbon formation on nickel-containing catalysts. J Catal 48:155-165

11. Pinilla JL, Suelves I, Lazaro MJ, Molinear R (2010) Parametric study of the decomposition of methane using a NiCu/Al2O3 catalyst in a fluidized bed reactor. Int J Hydrogen Energy 35:9801-9809

12. Iwasa N, Yamane T, Takei M, Ozaki Jl, Arai M (2010) Hydrogen production by steam reforming of acetic acid: comparison of conventional supported metal catalysts and metal-incorporated mesoporous smectite-like catalysts. Int J Hydrogen Energy 35:110-117

13. Zeng J, Xiao R, Zeng D, Zhao Y, Zhang H, Shen D (2016) High $\mathrm{H}_{2} / \mathrm{CO}$ ratio syngas production from chemical looping gasification of sawdust in a dual fluidized bed gasifier. Energy Fuels 30:1764-1770

14. Cao Y, Gao Z, Jin J, Zhou H, Cohron M, Zhao H, Liu H, Pan W (2008) Synthesis gas production with an adjustable $\mathrm{H}_{2} / \mathrm{CO}$ ratio through the coal gasification process: effects of coal ranks and methane addition. Energy Fuels 22:1720-1730

15. Dalena F, Senatore A, Basile M, Knani S, Basile A, Iulianelli A (2018) Advances in methanol production and utilization, with particular emphasis toward hydrogen generation via membrane reactor technology. Membranes 8:98-124

16. Halmann M, Steinfeld A (2006) Fuel saving, carbon dioxide emission avoidance, and syngas production by tri-reforming of flue gases from coal- and gas-fired power stations, and by the carbothermic reduction of iron oxide. Energy 31:3171-3185

17. Halmann M, Steinfeld A (2006) Thermoneutral tri-reforming of flue gases from coal- and gas-fired power stations. Catal Today 115:170-178

Publisher's Note Springer Nature remains neutral with regard to jurisdictional claims in published maps and institutional affiliations. 